\title{
Active and passive information behaviour of the professoriate: A descriptive comparative pattern analysis
}

\begin{tabular}{|c|c|}
\hline \multicolumn{2}{|c|}{$\begin{array}{l}\text { Authors: } \\
\text { Simeon A. Nwone }{ }^{1} \\
\text { Stephen M. Mutula }\end{array}$} \\
\hline \multicolumn{2}{|c|}{$\begin{array}{l}\text { Affiliations: } \\
{ }^{1} \text { Information Studies } \\
\text { Programme, School of Socia } \\
\text { Sciences, College of } \\
\text { Humanities, University of } \\
\text { KwaZulu-Natal, } \\
\text { Pietermaritzburg, } \\
\text { South Africa }\end{array}$} \\
\hline \multicolumn{2}{|c|}{$\begin{array}{l}{ }^{2} \text { School of Management, IT } \\
\text { and Governance, College of } \\
\text { Law and Management } \\
\text { Studies, University of } \\
\text { KwaZulu-Natal, } \\
\text { Pietermaritzburg, } \\
\text { South Africa }\end{array}$} \\
\hline \multicolumn{2}{|c|}{$\begin{array}{l}\text { Corresponding author: } \\
\text { Simeon Nwone, } \\
\text { simeonnwone@gmail.com }\end{array}$} \\
\hline \multicolumn{2}{|c|}{$\begin{array}{l}\text { Dates: } \\
\text { Received: } 16 \text { Oct. } 2019 \\
\text { Accepted: } 19 \text { Apr. } 2020 \\
\text { Published: } 30 \text { June } 2020\end{array}$} \\
\hline \multicolumn{2}{|c|}{$\begin{array}{l}\text { How to cite this article: } \\
\text { Nwone, S.A. \& Mutula, S.M., } \\
\text { 2020, 'Active and passive } \\
\text { information behaviour of the } \\
\text { professoriate: A descriptive } \\
\text { comparative pattern analysis', } \\
\text { South African Journal of } \\
\text { Information Management } \\
\text { 22(1), a1161. https://doi.org/ } \\
\text { 10.4102/sajim.v22i1.1161 }\end{array}$} \\
\hline \multicolumn{2}{|c|}{$\begin{array}{l}\text { Copyright: } \\
\text { (C) 2020. The Authors. } \\
\text { Licensee: AOSIS. This v } \\
\text { is licensed under the } \\
\text { Creative Commons } \\
\text { Attribution License. }\end{array}$} \\
\hline \multirow[b]{2}{*}{ Read online: } & \\
\hline & $\begin{array}{l}\text { Scan this QR } \\
\text { code with your } \\
\text { smart phone or } \\
\text { mobile device } \\
\text { to read online. }\end{array}$ \\
\hline
\end{tabular}

Background: The study explored and analysed patterns in active and passive information behaviour of the professoriate in different information sources in teaching and research context. Exploring patterns in human information behaviour fills the knowledge gaps in this under-researched area, besides having practical significance.

Objectives: The study explored the patterns in active and passive information behaviour in different information sources used by the professoriate in the social sciences and humanities in three federal universities in Nigeria.

Methods: The study used a descriptive survey to explore the active and passive information behaviour of the professoriate. The sample consisted of 246 professors from the social sciences and humanities departments at three federal universities in Nigeria. Data were collected using an adapted questionnaire and analysed descriptively using the Statistical Package for Social Sciences.

Results: The patterns that emerged across electronic resources, media, print sources, interpersonal and academic gathering, in three usage categories, showed both consistent and divergent results. A broad pattern in frequently-used sources revealed that the more active information seeking takes place in an information source, the more chances of passive encounters, and vice versa. This pattern is, however, consistent in electronic resources, print sources, and academic gathering, but differs in media and interpersonal sources. Media has more instances of passive encounters than active usage whilst in interpersonal sources, information encountered in active engagements with professional colleagues did not yield significant result.

Conclusion: Exploring patterns in human information behaviour is still evolving, with the benefit of advancing a better understanding of active and passive information behaviour at a micro level.

Keywords: information behaviour; professoriate; information sources; seeking; encountering.

\section{Introduction}

Active and passive information behaviour constitute part of the holistic human behaviour concerning uses of information resources and the channels through which information reaches users. Active information behaviour is the purposeful or intentional search for information to satisfy a goal, and usually requires the information seeker to make a demand on an information system in the form of request, search or query (Wilson 2000). Passive information behaviour, on the other hand, refers to the opportunistic discovery of information (Erdelez 1997; Toms \& McCayPeet 2009) and describes the unexpected encountering of useful information whilst engaged in other activities (Erdelez 1997). Academic faculties at the professorial level use both formal and informal methods to seek information to meet their teaching and research goals (Xuemei 2010) and, in the process, encounter valuable information for future use. Over the years, print sources have dominated the academic information environment, and encountering valuable information in them is not a new phenomenon, as serendipitous encounters have been the focus of researchers for many decades (McNally, Prier \& MacMillan 2011; Van Andel 1994).

Furthermore, with the advent of information technology, electronic information resources have changed the way information is accessed, stored and used conveniently, and have become a dominant tool in the academia influencing scholarly communication in an unprecedented manner (Tahir, Mahmood \& Shafique 2008). Besides the use of print sources for teaching and research, 
professoriates also seek information using electronic information resources such as online databases and electronic journals (Engel, Robbins \& Kulp 2011; Rupp-Serrano \& Robbins 2013). These platforms have equally become potent grounds for discovering useful information that can be stored electronically for future reference (Jiang, Liu \& Chi 2015).

Active usage of information resources by the professoriate are found to differ across academic discipline, age, geographical boundaries, context (e.g. teaching, research) and individual orientation and disposition towards information resources (Hemminger et al. 2007; Marouf \& Anwar 2010; Nwone \& Mutula 2018; Rupp-Serrano \& Robbins 2013; Singh \& Satija 2007; Xuemei 2010). Generally, social science professors use electronic resources more than their counterparts in humanities, preferring electronic resources for research and print resources for teaching (Xuemei 2010). Social science professoriate studying stateless nations, besides using traditional methods, used the World Wide Web and email for locating relevant information (Meho \& Haas 2001), whilst the professoriate of social science at the University of the West Indies preferred textbooks for teaching, followed by journals and monographs, and relied on e-journals and online database for current information (Hannah 2005). The professoriate in the Xuemei (2010) study used more electronic resources than print sources to meet their research needs, whilst their preference for electronic information resources varied across professorial ranks and disciplines. Professoriates in social sciences in Kuwait show heavy reliance on books and print journals for teaching and research due to lack of scholarly databases in Arabic. Conferences, subject experts and colleagues were their main informal sources of information (Marouf \& Anwar 2010). For research endeavours, faculty of education professoriates in the United States used scholarly journals, internet resources and books, whilst face-to-face communication with colleagues was their informal means of obtaining information (Rupp-Serrano \& Robbins 2013). Law faculty professors relied more on textbooks and law reports for information seeking. Their use of online databases was significantly low, implying heavy dependence on print over electronic sources (Aforo \& Lamptey 2012; Thanuskodi 2009). In all these instances, there are bound to be some measures of information encountering. Information can be encountered more frequently in some sources and occasionally in other sources, whereas in other sources, information encountering rarely occurs.

The value of information encountered in an active process is of practical significance. It presents the need for platform developers to recognise the value of 'serendipitous information' and create a clipboard for users to place information encountered for future reference. This may require users to highlight the information of interest with an option to send the highlighted information to a 'serendipity clipboard'. It can help the library to re-align library services and channel marketing campaigns on frequently-used sources with high chances of serendipity.
Although studies (Erdelez 1997; Williamson 1998) have shown that useful information can be encountered in the process of deliberate information seeking and even when leisurely exposed to different forms of media, researchers have given little attention to this passive information behaviour. The role of passive information behaviour or information that is accidentally acquired, especially in an academic context, has not received adequate attention in information science literature. Haley, Wiessner and Robinson (2009) focused on encountering new information and perspectives in constructing knowledge in conference contexts. Foster and Ford (2003) examined the nature of serendipity in the information-seeking context of interdisciplinary scholars, whilst Marshall \& Bly (2004) explored how people share information they encountered in their everyday reading. Stewart and Basic (2014) explored information-encountering experiences of undergraduate students and the potential role of personal information collection, management, and retrieval in information literacy instruction. The paucity of studies on passive information behaviour of academic faculties exacerbates the scantiness of studies on the relationship between active and passive information behaviour. The closest study comparing active and passive information behaviour was carried out by Pálsdóttir (2007) on health and lifestyle information seeking of Icelanders. The study found that those active in information seeking were also active in information encountering, and those who were passive in either of the two styles of information seeking were passive in the other. This study is highly significant as it advances knowledge on the connection between active and passive information behaviour in information science literature.

Actively seeking information for teaching and research using search engines and/or online databases is associated with salient but passive information gathering. The significance of information passively encountered during active information seeking has become an interesting topic for researchers (Erdelez 1997; Foster \& Ford 2003; McBirnie 2008; Pálsdóttir 2007; Williamson 1998). Since active information seeking occurs in print and on digital platforms, and at an interpersonal level, passive information gathering is unsurprisingly expected and, in the view of Erdelez (2005:25), it is an integral part of the information-seeking process, not to be seen as a separate behaviour, describing it as a '... common element of users' behaviour'. The close association between these two activities warrants further empirical investigations. A cross analysis of patterns emanating from the associated information behaviours will make a significant theoretical contribution of advancing the understanding of human information behaviour at a micro level, besides laying a foundation for further empirical research.

This study focused on examining the active and passive information behaviour of the professoriate in selected universities in Nigeria and compared patterns inherent in the highly-correlated behaviour. Specifically, the patterns in the associated information behaviour will be examined across different information sources in three usage categories 
(frequently, occasionally and rarely) by the professoriate for teaching and research. The information sources are electronic and print sources, media, interpersonal and academic gathering.

\section{Literature review}

The literature review focused on empirical literature on active information behaviour (information-seeking behaviour) of the professoriate. Since literature that focused specifically on the professoriate are few, emphasis was placed on literature which included the professoriate population. A search on passive information behaviour in an academic faculties did not produce significant results, while are comparative literature on active and passive information behaviour is sparse. The reviewed literature unveiled the knowledge gaps filled by this study.

\section{Active information behaviour}

In a study of active information behaviour of the social science and humanities faculty in the United States, Xuemei (2010) showed that whilst social scientists tend to rely heavily on periodicals, humanities researchers rely more on books and primary sources. Overall, the respondents of the study used electronic resources to satisfy $58 \%$ of their research needs and print sources to satisfy $42 \%$ of their research needs. Despite the general preference for electronic information resources, individual differences exist amongst the professorial ranks and disciplines. A full professor in the history department was concerned about the availability of older materials in the discipline, justifying the relevance of print sources to his discipline. A professor in the African Studies department was not familiar with the library's electronic information resources and found it hard to evaluate electronic resources on the web, since the nature of his research relied more heavily on field studies and preferred print to the digitised. In Kuwait, the information-seeking behaviour of 10 professors, 25 associate professors and 19 assistant professors of social science (Marouf \& Anwar 2010) suggests that the majority of the professoriate were heavily dependent on books and journals for teaching and research purposes. The professoriate were constrained to using print sources written in Arabic because of the scarcity of online databases that offer scholarly information in Arabic. They relied on conferences, subject experts and colleagues as informal sources of information. Active information behaviour of the social science faculty at the University of Bahawalpur, Pakistan, revealed that the faculty used books, periodicals, indexes, abstracts for teaching and research (Tahir et al. 2008). The majority of the participants were not satisfied with the current stock of books related to their fields as they found them inadequate in meeting their research needs. There was no mention of electronic journals or online databases as part of information sources, suggesting that the university has not fully embraced information technology to access electronic resources. Discussion with seniors and colleagues, seminars, workshops and conferences constitute their informal sources of gathering information. The study participants include 40 lecturers, 40 assistant professors, 10 associate professors, and 10 professors (Bhatti 2010). A study of information seeking behaviour of social science faculty at the University of West Indies, Jamaica (Hannah 2005), observed that textbooks were the preferred source of information for teaching, followed by journals and monographs. For current awareness, respondents named current issues of journals, followed by online database searches. Information sources used for teaching and research included citations at the end of journal articles and citations at the end of the chapters of a book. Meho and Haas's (2001) study on information seeking of the social science faculty studying stateless nations across countries of the United States, United Kingdom, Germany, Canada, Australia, France, Italy, Netherlands, Switzerland and Turkey, showed that besides using traditional methods, social science professors used the World Wide Web and email for locating relevant information. It shows that these faculty members are aware of and utilise information technology to support their research. Studying active information behaviour of the education faculty in the United States, Rupp-Serrano and Robbins (2013) uncovered the heavy dependence on scholarly journals for research by the faculty, followed by internet resources and books. Browsing current issues of journals, attending conferences, following references or leads from articles and personal communication were the most frequent means of staying current. Face-to-face interaction with colleagues is the informal means of obtaining information. Purposeful information seeking in the Law faculty at the Central Law faculty in Salem, India, had five professors, seven senior lecturers, 19 lecturers and 25 guest lecturers as study participants (Thanuskodi 2009). The author observed that the Law faculty relied more on text books and law reports for information seeking, whilst the use of online databases was significantly low, indicating that the professoriate in Law relied more on print resources than electronic sources. A similar study of the Law faculty in Ghana reported the use of law reports, law journals and textbooks to seek information, and further buttressed the heavy reliance on print resources by the Law faculty (Aforo \& Lamptey 2012). The next section presents literature on passive information behaviour.

\section{Passive information behaviour}

Active information seeking has since dominated information science literature. The role of information acquired accidentally has not received sufficient empirical attention (Williamson 1998). Studies (Erdelez 1997; Foster \& Ford 2003; Pálsdóttir 2007; Williamson 1998) have shown that useful information can be encountered in the process of a deliberate search for information. The term 'incidental information acquisition' is seen as synonymous with 'accidental information discovery', suggesting that people find information unexpectedly as they engage in other activities. Some of the information, they did not know they needed until they heard or read it. McKenzie (2003) used the 
term 'active scanning', referring to people being aware of the possibility of finding useful information in certain places although they are not seeking specific information. Erdelez (1997:412) used the term 'information encountering' for 'memorable experiences of accidental discovery of useful or interesting information'. Wilson (1999) used the term 'passive attention' for the unintentional discovery of useful information. In addition, Wilson (1999) coined 'passive searching', where a person discovers relevant information in the process of seeking for information. The term active scanning was used by McKenzie (2003), referring to an awareness of the likelihood of discovering valuable information in media when the person is not seeking for any specific information.

Haley et al. (2009) conducted a collaborative qualitative enquiry into encountering new information and perspectives in constructing knowledge in conference contexts. Collaborators in the inquiry included conference coordinators, university faculty researchers, doctoral student research assistants, and conference attendees. The findings of their research focused on patterns that emerged through data analysis. Initial open coding of the data revealed a pattern of interaction and engagement with conference content at two different levels. Participants may engage in the material, they may state their intention to act based on the material, and participants are more likely to report engagement than action.

Foster and Ford (2003) applied a naturalistic inquiry into the nature of serendipity in the information-seeking context of interdisciplinary scholars, both as a problem-solving strategy and a sheer mode of knowledge acquisition. The outcome suggests that serendipity was widely experienced amongst the interdisciplinary researchers. Serendipitously discovered information impacts on the discovery process by reinforcing or strengthening the researcher's existing problem, conception or solution, and taking the researcher in a new direction, in which the problem conception or solution is reconfigured in some way (Foster \& Ford 2003). Besides the impact of serendipity, the nature of serendipitous information is revealed in two ways: (1) the unexpected finding of information, the existence, and/or location of which was unexpected rather than the value, and (2) the unexpected finding of information that also proved to be of unexpected value (Foster \& Ford 2003).

There is a dearth of research on passive information behaviour or information encountering of university faculties, especially at the professorial level. Besides, most previous studies (Foster \& Ford 2003; Haley et al. 2009; Pálsdóttir 2007) used qualitative approaches with small samples. Furthermore, besides Pálsdóttir $(2007,2010)$, who examined the connection between purposive information seeking and information encountering in a study of Icelanders' health and lifestyle information seeking, comparing patterns between active and passive information behaviour in an academic context have not gained much attention in library and information science literature. This paper presents analysis from a larger quantitative study on the information behaviour of the professoriate in selected federal universities in Nigeria. The aim of this paper is to explore patterns that emerged from the comparison of active (purposive) and passive (encountering) information behaviour of the university professoriate.

\section{Methodology}

The study used a descriptive survey design to examine the information-seeking behaviour of the professoriate. The population of the study comprised 246 members of the professoriate from the social sciences and humanities department at the University of Ibadan, University of Lagos and Obafemi Awolowo University. A census survey using questionnaires that consists of self-structured and adapted questions from previous studies was used to collect quantitative data from the professoriate. Reliability of the constructs in the data collection instrument measured 0.88 on the Cronbach's alpha scale. The researcher made use of professional research assistants to collect data from the professoriate through personal visits to their offices. The research assistants were very familiar with the three universities and have good experience in research data collection. Collecting data from the professors was a daunting task, because of their regular unavailability in their offices and often-busy schedules, thereby prolonging the period of data collection, which took approximately 7 months, from January to July 2016. At the University of Lagos, 86 questionnaires were distributed, 48 collected and 40 found fit for data analysis. At the University of Ibadan, 91 questionnaires were distributed, 76 collected and 70 were suitable for analysis. At Obafemi Awolowo University, 69 questionnaires were distributed, 60 questionnaires were retrieved and 55 were appropriate for analysis. In all, 246 questionnaires were distributed, 184 were collected and 165 questionnaires were fit and coded for data analysis. The data were analysed using descriptive statistics with the Statistical Package for the Social Sciences (IBM Corp., Armonk, New York, United States).

\section{Ethical consideration}

The study followed all ethical procedures stipulated by the University of KwaZulu-Natal ethical committee. Protocol reference number: HSS/1444/015D.

\section{Results}

The results of the professoriate's active and passive information behaviour patterns are presented below.

\section{Professoriate active information behaviour}

The results presented in Table 1 on the active information seeking of the professoriate, describe the various information source categories (electronic resources, media, print resources, interpersonal sources, academic gathering) used by the professoriate to seek information for teaching and research. 
TABLE 1: Information sources used for teaching and research $(N=165)$

\begin{tabular}{|c|c|c|c|c|c|c|c|c|}
\hline \multirow{2}{*}{$\begin{array}{l}\text { How often do you use the under listed } \\
\text { information sources for teaching and } \\
\text { research }\end{array}$} & \multicolumn{2}{|c|}{ Frequent } & \multicolumn{2}{|c|}{ Occasionally } & \multicolumn{2}{|c|}{ Rarely } & \multicolumn{2}{|c|}{ Never } \\
\hline & Frequency & $\%$ & Frequency & $\%$ & Frequency & $\%$ & Frequency & $\%$ \\
\hline \multicolumn{9}{|l|}{ Electronic resources } \\
\hline Electronic journals & 119 & 71.5 & 42 & 25.5 & 5 & 3.0 & 0 & 0 \\
\hline Web portals & 87 & 52.7 & 48 & 29.1 & 23 & 13.9 & 0 & 0 \\
\hline Web sites & 84 & 50.9 & 53 & 32.1 & 23 & 13.9 & 0 & 0 \\
\hline Online catalogues & 9 & 5.5 & 84 & 50.9 & 52 & 31.5 & 0 & 0 \\
\hline Listservs & 0 & 0 & 12 & 7.3 & 118 & 71.5 & 0 & 0 \\
\hline File Transfer Protocol & 0 & 0 & 3 & 1.8 & 18 & 10.9 & 137 & 83 \\
\hline \multicolumn{9}{|l|}{ Media } \\
\hline Newspaper & 3 & 1.8 & 129 & 77.6 & 34 & 20.6 & - & - \\
\hline Radio & 2 & 1.2 & 62 & 37.6 & 81 & 49.1 & 13 & 7.9 \\
\hline \multicolumn{9}{|l|}{ Print resources } \\
\hline Journal articles & 165 & 100 & 0 & 0 & 0 & 0 & 0 & 0 \\
\hline Textbooks & 163 & 98.8 & 2 & 1.2 & 0 & 0 & 0 & 0 \\
\hline Encyclopaedia & 69 & 41.8 & 83 & 50.3 & 13 & 7.9 & 0 & 0 \\
\hline Maps & 31 & 18.8 & 19 & 11.5 & 77 & 46.7 & 0 & 0 \\
\hline Magazine & 4 & 2.4 & 62 & 37.6 & 84 & 50.9 & 14 & 8.5 \\
\hline \multicolumn{9}{|l|}{ Interpersonal sources } \\
\hline Interaction with colleagues & 101 & 61.2 & 55 & 33.3 & 7 & 4.2 & 0 & 0 \\
\hline Interaction with friends & 2 & 1.2 & 26 & 15.8 & 97 & 58.8 & 25 & 15.2 \\
\hline \multicolumn{9}{|l|}{ Academic gathering } \\
\hline Conference proceedings & 71 & 43 & 88 & 53.3 & 4 & 2.4 & 0 & 0 \\
\hline Seminar & 50 & 30.3 & 107 & 64.8 & 4 & 2.4 & 0 & 0 \\
\hline Workshop & 43 & 26.1 & 100 & 60.6 & 19 & 11.5 & 0 & 0 \\
\hline
\end{tabular}

\section{Professoriate passive information behaviour}

The respondents were asked whether they have encountered information in any of the information sources listed whilst deliberately seeking information to be used for teaching and research. Table 2 shows the results.

\section{Comparing active and passive information behaviour - Descriptive analysis}

Customarily, information seeking has been described as seeking information on purpose, nevertheless, a small but increasing number of studies have recognised information encountering as being a part of information-seeking behaviour (Abrahamson \& Fisher 2007; Foster 2004; Hider 2006; McKenzie 2003; Wilson 1999). Since encountering information happens during a purposeful search, the data on (passive) information encountering were juxtaposed with (active) purposeful information seeking. The results revealed that the ratio of frequent encounters against the frequent information seeking in online databases (49.1\%; 77\%), electronic journals $(50.3 \% ; 71.5 \%)$ and web portals $(22.4 \%$; $52.7 \%)$ is comparatively higher in relation to websites $(4.2 \%$; $50.9 \%)$, where the professoriate encountered less $(4.2 \%)$ 'frequent' information in relation to those (50.9\%) that admittedly used websites for information seeking. Expectedly, since the 'frequent' use of email (9.7\%), online catalogue (5.5\%), listservs ( $0 \%$ ), and File Transfer Protocol ( $0 \%)$ for teaching and research were low, information encountered on these media was also low. The findings here imply that the more information is 'frequently' sought in online databases, electronic journals and web portals, the more chances of encountering new information. In websites where the professoriates do more 'browsing', there are less chances of encountering information for teaching and research. For email and online catalogues, the low rate of information encountered in these sources simply corresponds to its low frequency of use in seeking information for teaching and research. In contrast, there are more reported cases of occasional information encounters in online databases (49.1\%), electronic journals (50.3\%), web portals (56.4\%) and websites $(82.4 \%)$ by the professoriate in comparison to their counterparts' occasional active usage at $22.4 \%$ (online databases), 25.5\% (electronic journals), 29.1\% (web portals) and $32.1 \%$ (websites). For online databases and electronic journals, the rate of frequent information encounter is same as for occasional encounters and further buttresses the high rate of both frequent and occasional information encountered in these sources. For web portals (56.4\%), and particularly websites $(82.4 \%)$, there are more reported cases of occasional information encounters $(22.4 \%)$ than frequent $(4.2 \%)$. For websites, the high occasional information encounters could be as a result of its browsing nature where, expectedly, the professoriate are more likely to occasionally rather than frequently encounter information. For email, the relatively few cases of its active but occasional (20\%) usage correspond to the few intances of occasional information encounters (12.1\%). This implies that not so much information is encountered, either frequently or occasionally, in the use of email for 
TABLE 2: Sources of information encounter $(N=165)$.

\begin{tabular}{|c|c|c|c|c|c|c|c|c|}
\hline \multirow{2}{*}{$\begin{array}{l}\text { Have you encountered information for } \\
\text { teaching and research in any of the } \\
\text { following information sources }\end{array}$} & \multicolumn{2}{|c|}{ Frequent } & \multicolumn{2}{|c|}{ Occasionally } & \multicolumn{2}{|c|}{ Rarely } & \multicolumn{2}{|c|}{ Never } \\
\hline & Frequency & $\%$ & Frequency & $\%$ & Frequency & $\%$ & Frequency & $\%$ \\
\hline \multicolumn{9}{|l|}{ Electronic resources } \\
\hline Online databases & 81 & 49.1 & 83 & 50.3 & 1 & 0.6 & 0 & 0 \\
\hline Web portals & 37 & 22.4 & 93 & 56.4 & 31 & 16.8 & 0 & 0 \\
\hline Web sites & 7 & 4.2 & 136 & 82.4 & 19 & 11.5 & 0 & 0 \\
\hline Online catalogues & 1 & 0.6 & 24 & 14.5 & 108 & 65.5 & 26 & 15.8 \\
\hline Listservs & 0 & 0 & 18 & 10.9 & 116 & 70.3 & 23 & 13.9 \\
\hline File Transfer Protocol & 0 & 0 & 2 & 1.2 & 12 & 7.3 & 141 & 85.5 \\
\hline \multicolumn{9}{|l|}{ Media } \\
\hline Newspaper & 19 & 11.5 & 66 & 40.0 & 80 & 48.5 & 0 & 0 \\
\hline Television & 6 & 3.6 & 50 & 30.3 & 107 & 64.8 & 2 & 1.2 \\
\hline Radio & 1 & 0.6 & 30 & 18.2 & 130 & 78.8 & 2 & 1.2 \\
\hline Journal articles & 140 & 84.8 & 25 & 15.2 & 0 & 0 & 0 & 0 \\
\hline Textbooks & 140 & 84.8 & 25 & 15.2 & 0 & 0 & 0 & 0 \\
\hline Encyclopaedia & 25 & 15.2 & 113 & 68.5 & 24 & 14.5 & 0 & 0 \\
\hline Magazine & 9 & 5.5 & 11 & 6.7 & 140 & 64.8 & 0 & 0 \\
\hline Maps & 3 & 1.8 & 21 & 12.7 & 57 & 34.5 & 40 & 24.2 \\
\hline \multicolumn{9}{|l|}{ Interpersonal sources } \\
\hline Interaction with colleagues & 5 & 3.0 & 138 & 83.6 & 22 & 13.3 & 0 & 0 \\
\hline Interaction with friends & 2 & 1.2 & 17 & 10.3 & 114 & 69.1 & 27 & 16.4 \\
\hline \multicolumn{9}{|l|}{ Academic gathering } \\
\hline Conference proceedings & 33 & 20 & 128 & 77.6 & 4 & 2.4 & 0 & 0 \\
\hline Seminar & 14 & 8.5 & 144 & 87.3 & 6 & 3.6 & 0 & 0 \\
\hline Workshop & 6 & 3.6 & 147 & 89.1 & 10 & 6.1 & 0 & 0 \\
\hline
\end{tabular}

seeking information for teaching and research purposes. For the online catalogue, the number of professoriate that admitted encountering information occasionally (14.5\%) was more than those that encountered information frequently $(0.6 \%)$. This figure is low compared to those that use the online catalogue actively but occasionally. The reason could be that the online catalogue does not offer so much information, but is rather just a guide to library resources. It is therefore, expected that encountering information in this medium could only occur in a few occasional instances, bearing in mind the apparent challenges of accessing library information resources in the Nigerian academic environment. In the case of listserv and File Transfer Protocol, the few cases of occasional information encounters might well have been slightly exaggerated because they are hardly used and have few reported cases of occasional usage. The patterns in rare information encountering in electronic resources are anticipated since there are more cases of frequent and occasional information encounters in online journals and electronic databases; it is not surprising, therefore, to see that only a few of the professoriate rarely encounter information in these sources.

\section{Comparing patterns in active and passive information behaviour}

\section{Electronic resources - Frequent}

The patterns (Figure 1) that emerged when data on purposeful information seeking (active) was compared with information encountering (passive) on the 'frequent' dimension shows more active usage of online databases,

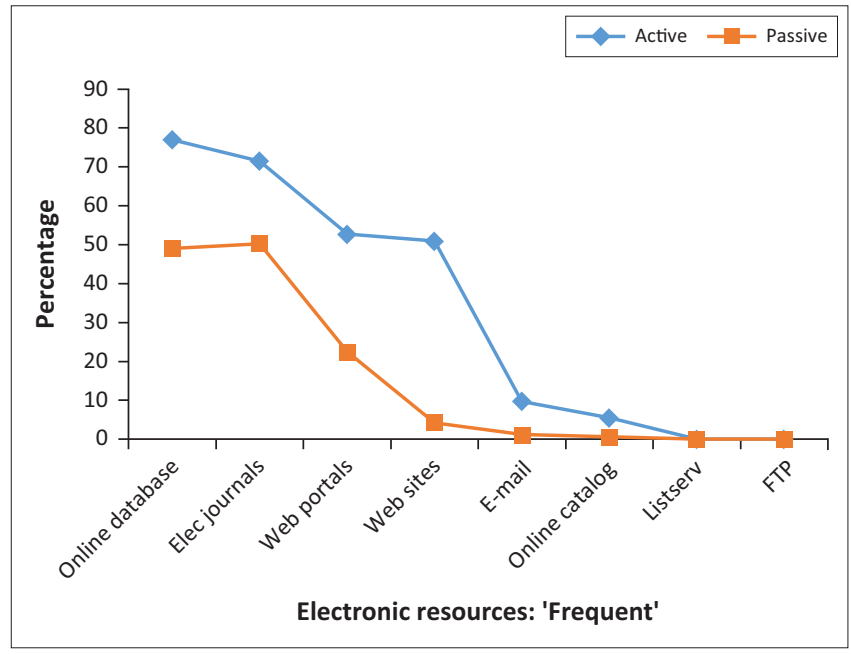

Elec, Electronic; FTP, File Transfer Protocol.

FIGURE 1: Comparing active and passive use of electronic resources - Frequent.

electronic journals and web portals, and less of email, online catalogues and listservs. Information encountering follows a similar pattern, with the exception of websites, where the gap seems wider. The pattern revealed two groups of datasets. One group comprised online database, e-journals, web portals and websites, and the second group comprised email, online catalogue and listservs. There are more active and passive information behaviours in the first group, and less in the second group. The pattern shows that the more active information seeking takes place in an information source, the more the chances of encountering new information, and vice versa. 


\section{Electronic resources - Occasionally}

In the occasional instance, two groups of datasets emerged. In the first group, and on the active and passive paths, online databases, e-journals, web portals and websites appear to have a consistent pattern but veered significantly along the passive path in websites. Passive information encountering was more along the paths of online databases, e-journals, web portals and websites on 'occasional' instances, implying a higher 'occasional' rate of information encountering in those sources in relation to their active usage. In the second group, emails, online catalogues, listservs and File Transfer Protocol behaved consistently along the passive path, and in comparison, online catalogues veered significantly along the active path. Overall, the pattern shows more instances of occasional (passive) information encountering in the first group than in the second group compared with active instances (Figure 2).

\section{Electronic resources - Rarely}

In the 'rarely' electronic resource category (Figure 3), two groups of datasets surfaced. The first set, namely, online

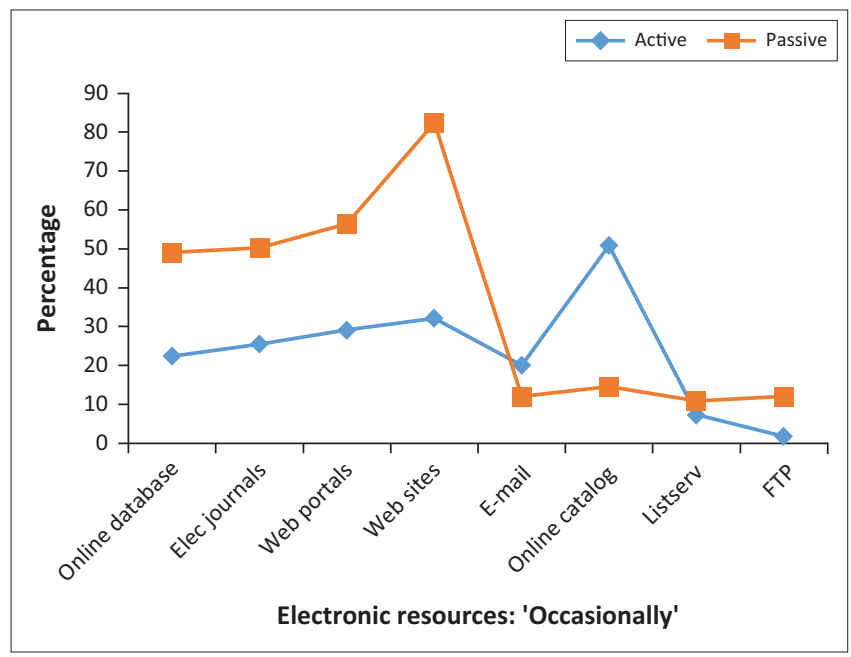

Elec, Electronic; FTP, File Transfer Protocol

FIGURE 2: Comparing active and passive use of electronic resources-Occasionally.

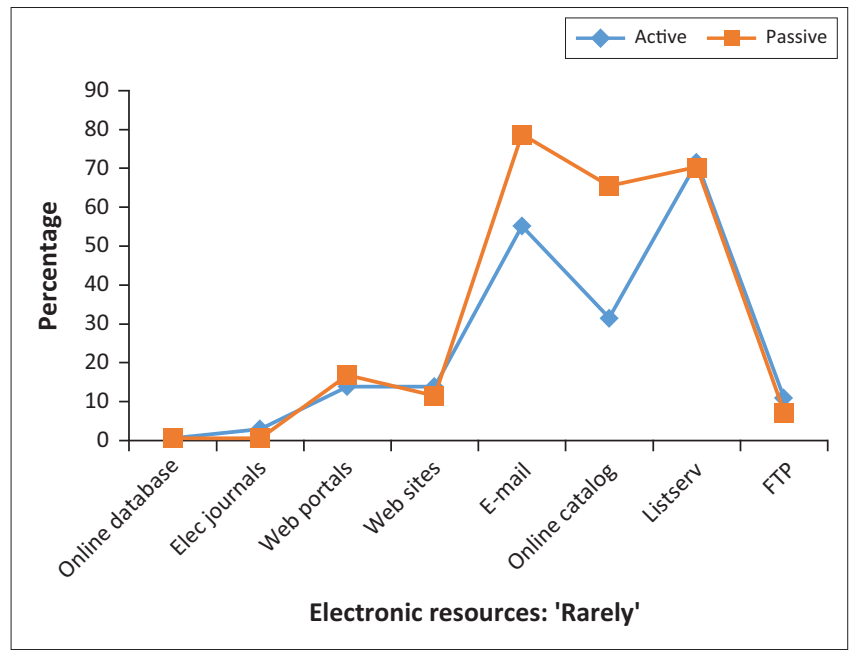

Elec, Electronic; FTP, File Transfer Protocol

FIGURE 3: Comparing active and passive use of electronic resources - Rarely. databases, e-journals, web portals and websites, appeared on the downward slope on both active and passive paths and implies that a low usage of these sources amounts to 'rare' information encounters in the same sources. The second group, namely, emails, online catalogues and listservs, has a higher rate of 'rare' usage on the active and passive paths, with passive instances more on email and listserv. This implies that information is 'rarely' encountered in these sources and corresponds to their low usage for purposeful information seeking. The broad pattern in the rarely category somewhat reflects the inverse of the frequent category, suggesting that instances of rare information encountered correspond to rare usage of those sources.

\section{Comparing active and passive use of information in media resources}

\section{Media sources - Frequent}

In the media category (Figure 4), the pattern shows that newspaper, television and radio are seldom used 'frequently' by the professoriate for teaching and research, and explains the downwards nature of the active curve compared with the passive curve, where the points for newspaper and television are far above its active counterparts. This implies that the professoriate encounter more 'frequent' information in newspaper and television, as opposed to deliberately using them to access information (for teaching and research). In the case of radio, there is significantly no difference between the active and passive points, implying its low usage and rare information encountering. Overall, in media, instances of passive information encountering occur more frequently in newspaper and television than in radio, in comparison to the active usage of those sources.

\section{Media sources - Occasionally}

In the occasional instance (Figure 5), the active curve for the three media (newspaper, television and radio) appeared above the passive curve, depicting more instances of 'occasional' but purposeful usage compared to instances of

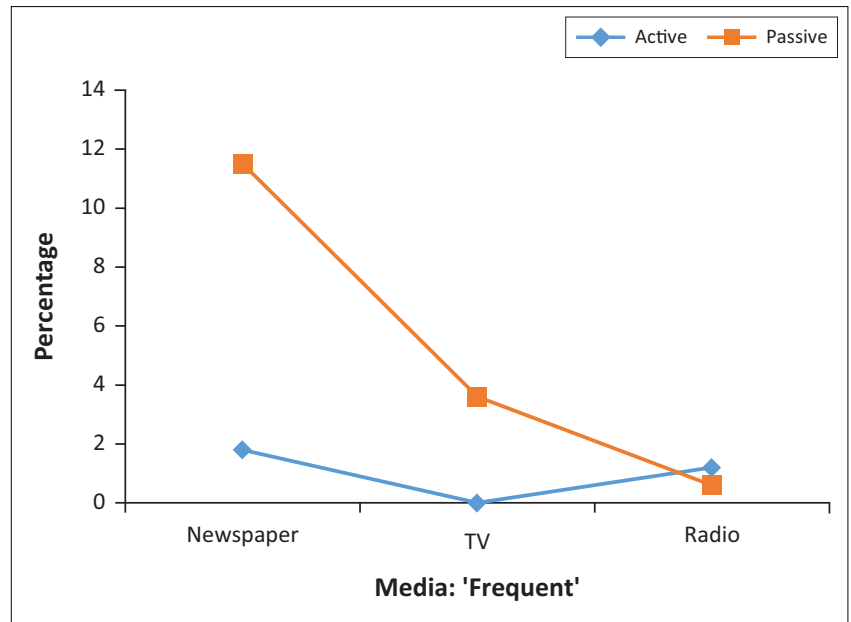

FIGURE 4: Comparing active and passive use of e-media resources - Frequently. 


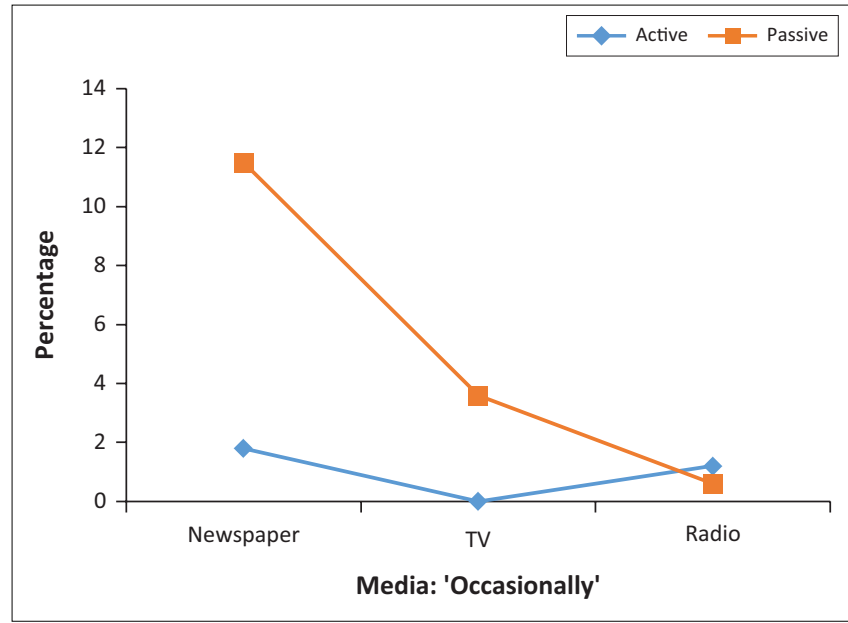

FIGURE 5: Comparing active and passive use of e-media resources-Occasionally.

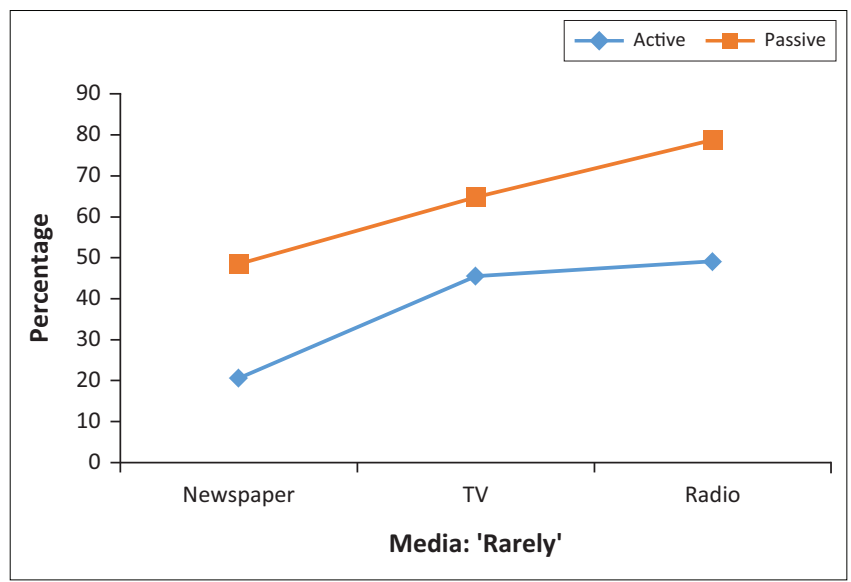

FIGURE 6: Comparing active and passive use of e-media resources - Rarely.

information encounters. In both cases, newspaper took the lead, followed by television and radio. The broad pattern shows that more instances of occasional (active) usage of newspaper, television and radio in that order correspond to (passive) information encountering in those sources in the same order.

\section{Media sources - Rarely}

The rare instance (Figure 6) is similar but opposite in direction to the occasional instance. There are more instances of rare information encounter in the three media than are purposively but rarely used. Newspaper recorded the least instances of rare information encounters in comparison with other media sources.

\section{Print resources - Frequent}

Two sets of patterns emerged on active use and information encountered in print sources. One pattern grouped the sources into two echelons: journals and textbooks at the upper echelon and encyclopaedia, maps and magazines at the lower part. The second pattern shows a close correlation between the purposeful (active) use of the sources and information encountered in those sources (Figure 7).

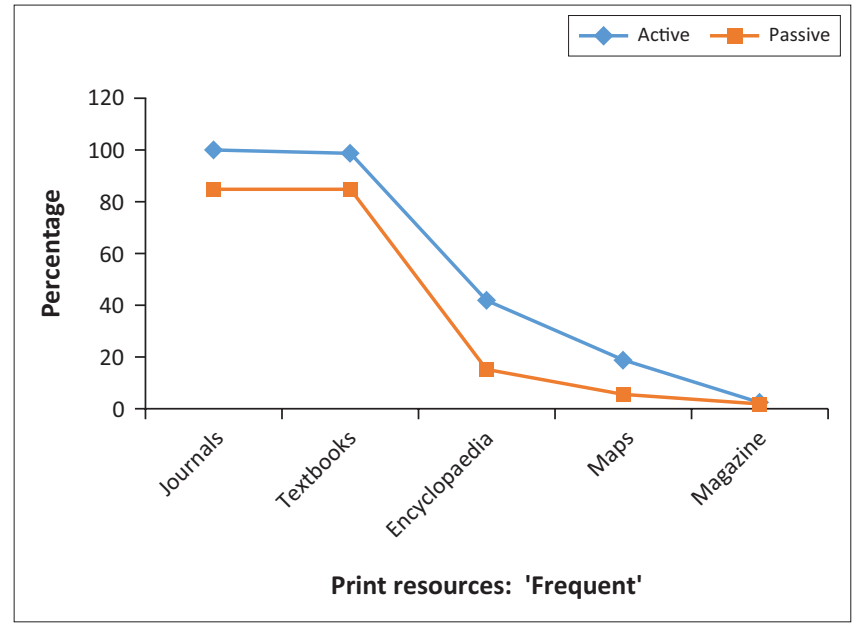

FIGURE 7: Comparing active and passive use of print resources - Frequent.

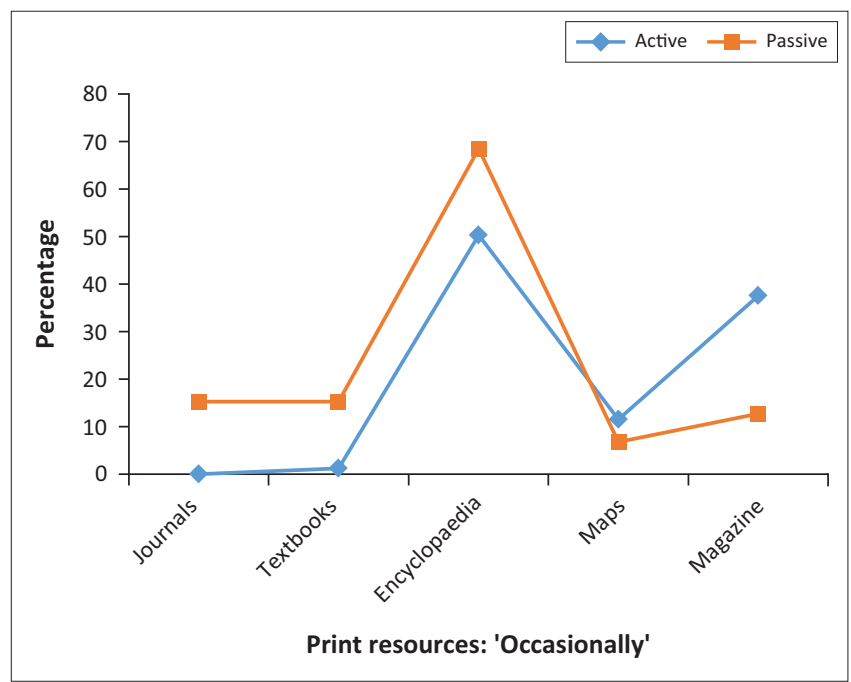

FIGURE 8: Comparing active and passive use of print resources - Occasionally.

\section{Print resources - Occasionally}

Superimposing active and passive data in the occasional category (Figure 8) shows that the highest occasional information encounters were with encyclopaedias, corresponding to high instances of active seeking in the medium in relation to other sources. At the lower ebb of the curve are few occasional cases of journal and textbook usage with more instances of information encounters. Maps and magazines, on the other hand, had more instances of actively seeking than passive encountering.

\section{Print sources - Rarely}

Comparing active and passive data on rare instances in print sources usage show no cases of rare information encounter in journals and textbooks. For encyclopaedias, rare instances of information encountered are slightly more but equivalent to its rare active usage. In the case of maps, there are very large cases of rare information encountering experiences, somewhat equivalent to the large number that rarely used the source. Whereas, for magazines, reported cases of rare active usage are higher in relation to the information encountered in the medium (Figure 9). 


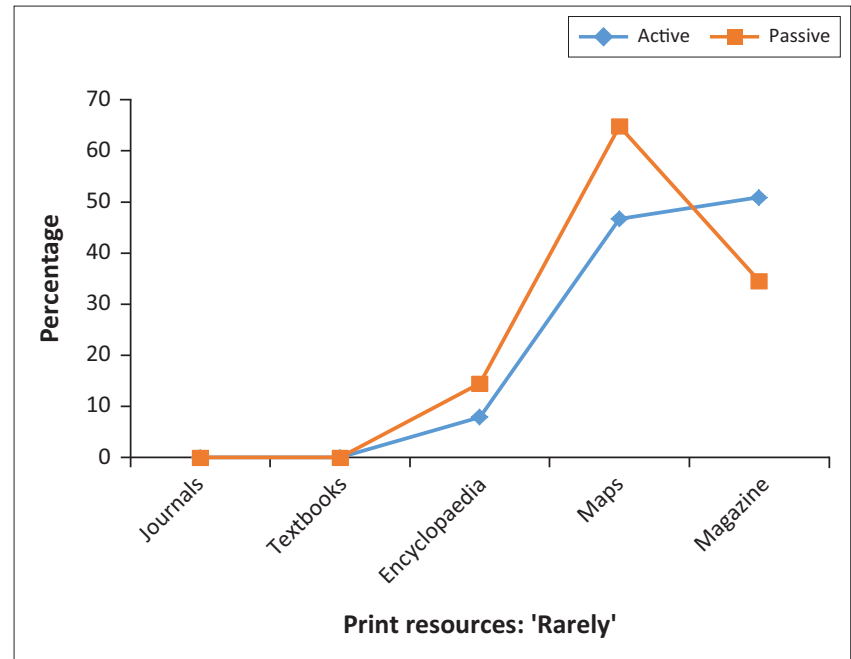

FIGURE 9: Comparing active and passive use of print resources - Rarely.

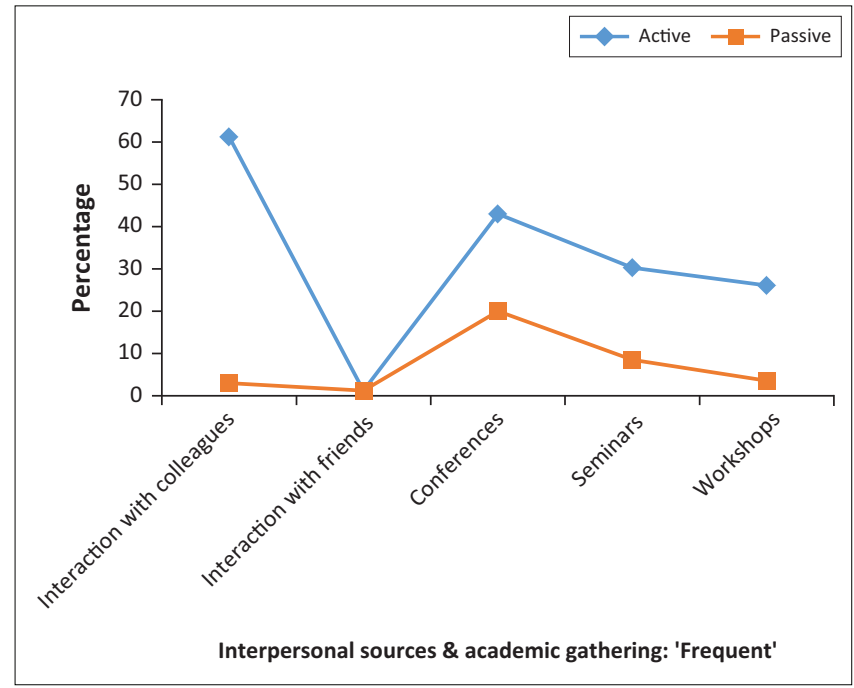

FIGURE 10: Comparing active and passive use of interpersonal sources - Frequent.

\section{Interpersonal and academic gathering sources - Frequent}

The pattern that emerged in the frequent category (Figure 10) when purposeful information seeking (active) was superimposed with information encountering (passive) data on interpersonal and academic gathering sources, shows that purposeful information seeking occurs more frequently with colleagues than with friends, and more in conferences than in seminars and workshops. Comparing both patterns shows huge difference between actively seeking information from colleagues and the insignificant information encountered from colleagues. On the paths of academic gathering, active information seeking occurs more in conferences than in seminars and workshops in that order. Information encountering follows a similar pattern, with conferences having more instances than seminars and workshops.

In the occasional category (Figure 11), there are more instances of occasional information encountering amongst colleagues than with friends, and more occasional information-encountering instances in conferences, seminars and workshops, with workshops having slightly more instances than seminars and conferences. Comparing both patterns depicts more instances of information encountering with colleagues than active instances, and on interaction with friends, both active and passive instances are insignificant. In academic gatherings, instances of information encountering surpasses active information seeking but in a corresponding manner, with relatively more instances of passive behaviour in workshops than in other groups (conferences and seminars), and relatively more active instances in seminars in relation to other groups (conferences and workshops).

In the rarely category (Figure 12), an overall view shows a corresponding similarity between active instances of rare information seeking and passive instances of rare information encountering in interaction with colleagues and friends, and in conferences, seminars and workshops. There are slightly more passive instance of rare information encounter than its active counterpart in interaction with friends. This implies that friends are hardly ever used to obtain academic

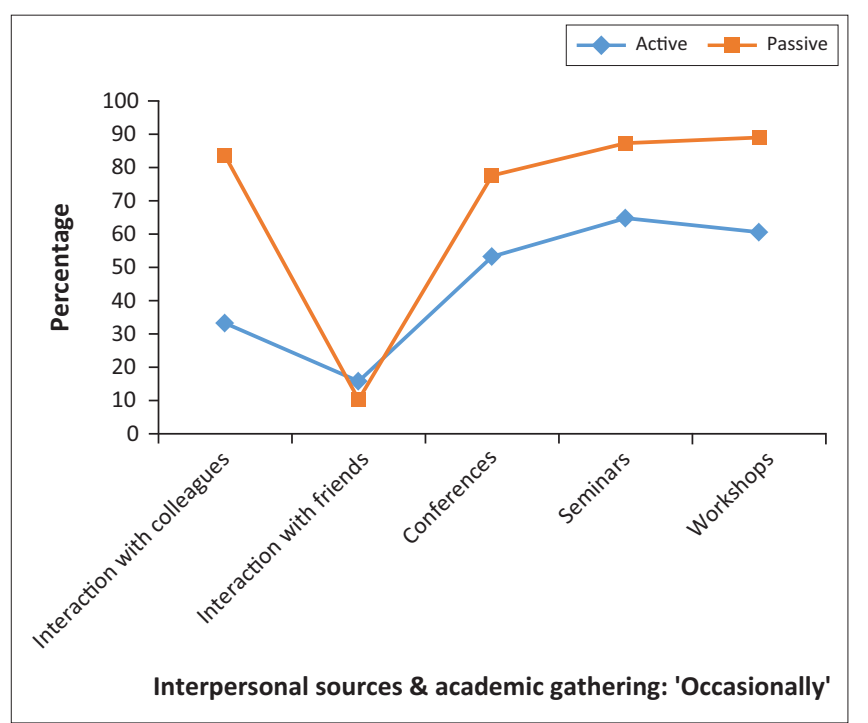

FIGURE 11: Comparing active and passive use of interpersonal sources-Occasionally.

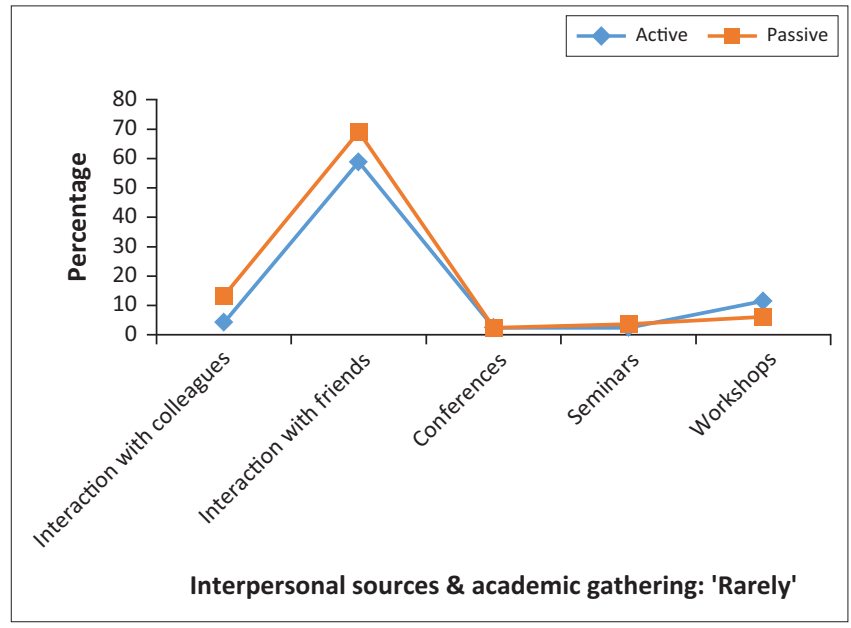

FIGURE 12: Comparing active and passive use of interpersonal sources - Rarely. 
information, and consequently, information encountering hardly ever occurs. Interaction with colleagues has a low passive instance of rare information encountering with a corresponding lower instance of active information seeking. Conferences, seminars and workshops behaved similarly, with insignificant, but slightly higher, cases of active information seeking than information encountering in workshops.

\section{Discussion}

A purposeful search to meet an information need is often associated with discovery of new information. The serendipitous nature of the discovered information does not reduce its relevance, as it can be set aside for future use. In this regard, researchers (Abrahamson \& Fisher 2007; Erdelez 2000; McKenzie 2003) have narrowed the line separating both types of behaviour, describing passive information seeking as a part of an active process. Invariably, information seekers will likely encounter more information in the medium they are often exposed to. With retrospect to disciplinary fields, professoriates in this study encounter and discover more useful information in print sources than in electronic resources. This supports the evidence that print sources are more convenient, especially for teaching. Even when electronic materials are downloaded from online databases, it is more often printed to ensure accessibility in an environment frequently plagued with erratic power supply. Whilst comparing patterns may look rudimental, it brought to the fore the proportion of purposeful information seeking and serendipity across the matrix of information sources and their usage frequencies. Exploring patterns in information behaviour is still at its infancy, and the outcome of previous research (Pálsdóttir 2007, 2010) that investigated this phenomenon is noteworthy, revealing a strong connection between active and passive information behaviour. Part of the phenomenon observed in this study is consistent with the trend in Pálsdóttir (2007, 2010); professoriates active in a source are equally active discoverers, especially in sources 'frequently' used. However, this trend is apparent in electronic resources, print sources and academic gatherings, but not in media and interpersonal sources. In a sense, the first group (electronic resources, print sources and academic gatherings) fits into traditional academic sources, often used more frequently in academic circles than the second group (media and interpersonal sources), and justifies the high cases of serendipity. The rather higher instances of frequent information encountering in the electronic media (newspaper and television) than its active usage to gather information for teaching and research is anticipated, since television is a platform for less active engagement where serendipitous information can be garnered in a more leisurely style. However, its occasional uses for academic purposes is emphasised in this study, as media reports can be used for academic reference purposes or case studies. Although professional colleagues are innate information custodians in academic settings, reported instances of frequent deliberate information seeking amongst them did not yield a corresponding magnitude of serendipitous instances, but at the occasional level, these instances were significant. This simply implies that sourcing academic information from colleagues is preferred, but does not necessarily produce a corresponding proportion of serendipity, which only occurs occasionally. Academic gatherings are usually occasional events where academics gain insights from paper presentations from other academic colleagues, thereby justifying the occasional instances of serendipitous events. The almost non-existent rare active and passive cases in academic gatherings portrays academic gatherings as an opulent platform for useful information gathering that occurs either frequently or occasionally, subject to individual contexts and perspectives.

\section{Conclusion}

The study examined and compared data on active and passive information behaviour of the professoriate in selected Nigerian universities. The results of pattern analysis on active and passive data in electronic resources, media, print sources, interpersonal and academic gathering categories across usage frequencies (frequently, occasionally and rarely) showed both similar and divergent results.

The pattern in sources frequently used revealed that the more active the engagement with an information source, the greater the chances of passive encounters, and vice versa. This pattern is, however, consistent in electronic resources, print sources, and academic gatherings, but varies in media and interpersonal sources. In media, instances of passive encounters are more than active usage. In interpersonal sources, the amount of information encountered during active engagements with professional colleagues is very low. Active interaction with friends and passive instances did not yield significant result.

In sources used occasionally, the pattern showed higher instances of information encountering in online databases, e-journals, web portals and websites in comparison with active usage. The pattern is consistent in print resources, academic gatherings and interaction with colleagues, but differed in media sources. In print sources, information encountering has lower instances, yet more than active uses, in journals and textbooks. In encyclopaedias, instances of occasional information encountering surpasses active cases, but varied in maps and magazines. Occasional but active engagement in media sources results in corresponding occasional passive encountering of information.

The pattern in rarely-used sources suggests that infrequent cases of rare usage of electronic resources correspond to rare cases of passive encounters in sources with high reported instances of frequent usage (online databases, e-journals, web portals and web sites), in comparison with sources (emails, online catalogues and listservs) with less reported instances of frequent usage. This pattern is consistent in print, interpersonal and academic gatherings. In print, 
sources (journals and textbooks) with high usage frequency have no instances of rare information encountering in relation to encyclopaedias, maps and magazines, with higher instances of rare but active usage and passive encounter. In interpersonal sources, the pattern is consistent in interaction with colleagues but not with friends. In academic gatherings, it is consistent across all dimensions of academic gathering. With reference to media, the pattern shows higher cases of rare passive encountering in relation to rare active exposure to all the media sources.

Exploring patterns in active and passive information behaviour is still developing, with the need for researchers to focus more on the dynamics of human information behaviour at a micro level, and in other information platforms, such as the social media.

\section{Recommendation}

The study recommends that library should re-aligning library services to accommodate both active and passive information behaviour of academic staff.

\section{Future research}

Future research should explore patterns in information behaviour of other academic groups and in various social media platforms.

\section{Acknowledgements}

The financial assistance of the National Institute for the Humanities and Social Sciences Council for the Development of Social Science Research in Africa (NIHSS-CODESRIA) towards this research is hereby acknowledged. Opinions expressed and conclusions arrived at are those of the authors and are not necessarily to be attributed to the NIHSSCODESRIA.

\section{Competing interests}

The authors have declared that no competing interest exist.

\section{Author's contributions}

S.A.N. originated the research idea, the work was an excerpt from his doctoral research at the University of KwaZuluNatal. He conceptualised and drafted the work, collected and analysed data, and wrote the report. S.M. supervised the entire research project. He refined the idea and the entire report.

\section{Funding information}

The financial assistance of the National Institute for the Humanities and Social Sciences Council for the Development of Social Science Research in Africa (NIHSS-CODESRIA) towards this research is hereby acknowledged. Opinions expressed and conclusions arrived at are those of the authors and are not necessarily to be attributed to the NIHSSCODESRIA.

\section{Data availability statement}

Data sharing is not applicable to this article as no new data were created or analysed in this study.

\section{Disclaimer}

The views and opinions expressed in this article are those of the authors and do not necessarily reflect the official policy or position of any affiliated agency of the authors.

\section{References}

Abrahamson, J. \& Fisher, K.E., 2007, 'What's past is prologue: Towards a general model of lay information mediary behaviour', Information Research 12(4), 65-72.

Aforo, A.A. \& Lamptey, R.B., 2012, 'Information needs and seeking behaviour of law lecturers in Kwame Nkrumah University of Science and Technology, Kumasi, Ghana', International Research Journal of Arts and Social Sciences 1(4), 75-80.

Bhatti, R., 2010, 'Information needs and information-seeking behaviour of faculty members at the Islamia University of Bahawalpur', Library Philosophy and Practice (e-journal), Paper 314

Engel, D., Robbins, S. \& Kulp, C., 2011, 'The information-seeking habits of engineering faculty', College and Research Libraries 72(6), 548-567. https://doi.org/10.5860/ crl-155

Erdelez, S., 1997, 'Information encountering: A conceptual framework for accidental information discovery', in P. Vakkari, R. Savolainen \& B. Dervin (eds.), Information seeking in context. Proceedings of an international conference on research in information needs, seeking, and use in different contexts (14-16 August, 1996, Tampere, Finland). pp. 412-421. Taylor Graham, Los Angeles, CA.

Erdelez, S., 2000, 'Towards understanding information encountering on the web', in Proceedings of the ASIS Annual Meeting (November 12-16, 2000, Chicago, IL). pp. 363-371.

Erdelez, S., 2005, 'Information encountering', in K.E. Fisher, S. Erdelez \& L.E.F. McKechnie (eds.), Theories of information behaviour, pp. 179-184, Information Today, Medford, NJ.

Foster, A., 2004, 'A non-linear model of information seeking behaviour', Journal of the American Society for Information Science and Technology 55(3), 228-237. https:// doi.org/10.1002/asi.10359

Foster, A. \& Ford, N., 2003, 'Serendipity and information seeking: An empirical study', Journal of Documentation 59(3), 321-340. https://doi.org/10.1108/002204 10310472518

Haley, K.J, Wiessner, C.A. \& Robinson, E., 2009, 'Encountering new information and perspectives: Constructing knowledge in conference contexts', The Journal of Continuing Higher Education 57(2), 72-82. https://doi.org/10.1080/07377360 902964384

Hannah, F., 2005, 'The information-seeking behaviour of social faculty at the University of West Indies, St Augustine Campus', Journal of Academic Librarianship 31(1), 67-72. https://doi.org/10.1016/j.acalib.2004.11.003

Hemminger, B.M., Lu, D., Vaughan, K.T.L. \& Adams, S.J., 2007, 'Information seeking behaviour of academic scientists', Journal of the American Society for Information Science and Technology 58(14), 2205-2225. https://doi.org/ 10.1002/asi.20686

Hider, P., 2006, 'Search goal revision in models of information retrieval', Journal of Information Science 32(4), 352-361. https://doi.org/10.1177/0165551506065811

Jiang, T., Liu, F. \& Chi, Y., 2015, 'Online information encountering: Modelling the process and influencing factors', Journal of Documentation 71(6), 1135-1157. https://doi.org/10.1108/JD-07-2014-0100

Marouf, L. \& Anwar, M.A., 2010, 'Information-seeking behaviour of the social sciences faculty at Kuwait University', Library Review 59(7), 532-547. https://doi. org/10.1108/00242531011065127

Marshall, C.C. \& Bly, S., 2004, 'Sharing encountered information: Digital libraries get a social life', in Proceedings of the 4th ACM/IEEE-CS Joint Conference on Digital Libraries, (June 7-11, 2004, Tucson, AZ). pp. 218-227.

McBirnie, A., 2008, 'Seeking serendipity: The paradox of control', Aslib Proceedings: New Information Perspectives 60(6), 600-618. https://doi.org/10.1108/000125 30810924294

McKenzie, P., 2003, 'A model of information practices in accounts of everyday life information seeking', Journal of Documentation 59(1), 19-40. https://doi.org/ $10.1108 / 00220410310457993$

McNally, A., Prier, C.K. \& MacMillan, D.W., 2011, 'Discovery of an $\alpha$-amino C-H arylation reaction using the strategy of accelerated serendipity', Science 334(6059), 1114-1117. https://doi.org/10.1126/science.1213920

Meho, L.I. \& Haas, S.W., 2001, 'Information seeking behaviour and use of social science faculty studying stateless nations: A case study', Library and Information Science Research 23, 5-25. https://doi.org/10.1016/S0740-8188(00)00065-7

Nwone, S.A. \& Mutula, S., 2018, 'Information behaviour of the professoriate in selected universities in Nigeria', South African Journal of Library and Information Science 84(1), 20-34. https://doi.org/10.7553/84-1-1733 
Pálsdóttir, Á., 2007, 'Patterns of information seeking behaviour: The relationship between purposive information seeking and information encountering', in P.A. Bath et al. (eds.), ISHIMR 2007: The Twelfth International Symposium on Health Bath et al. (eds.), ISHIMR 2007: The Twelfth International Symposium on Health Information Management Research: Sheffield, 18-20 July: Proceedings, University
of Sheffield Centre for Health Information Management Research, University of of Sheffield Centre for Health
Sheffield, Sheffield, pp. 3-15.

Pálsdóttir, Á., 2010, 'The connection between purposive information seeking and information encountering: A study of Icelanders' health and lifestyle information
seeking', Journal of Documentation 66(2), 224-244. https://doi.org/10.1108/ seeking', Journal of

Rupp-Serrano, K. \& Robbins, S., 2013, 'Information seeking habits of education faculty', College \& Research Libraries 74(2), 131-141. https://doi.org/10.5860/crl-322

Singh, K.P. \& Satija, M.P., 2007, 'Information seeking behaviour of agricultural scientists with particular reference to their information seeking strategies', Annals of Library and Information Studies 54, 13-220.

Stewart, K.N. \& Basic, J., 2014, 'Information encountering and management in information literacy instruction of undergraduate students', International Journal of Information Management 34(2), 74-79. https://doi.org/10.1016/j.ijinfomgt. 2013.10.007

Tahir, M., Mahmood, K. \& Shafique, F., 2008, 'Information needs and informationseeking behaviour of arts and humanities teachers: A survey of the University of the Punjab, Lahore, Pakistan', Library Philosophy and Practice (e-journal), Paper 227.
Thanuskodi, S., 2009, 'Information-seeking behaviour of law faculty at Central Law College, Salem', Library Philosophy and Practice (e-journal), Paper 282.

Toms, E.G. \& McCay-Peet, L., 2009, 'Chance encounters in the digital library', in M. Agosti, J. Borbinha, S. Kapidakish, C. Papatheodorou \& G. Tsakonas (eds.), ECDL'09. Proceedings of the 13th European Conference on Research and Advanced Technology for Digital Libraries, Corfu, Greece, pp. 192-202, Springer Verlag, Berlin.

Van Andel, P., 1994, 'Anatomy of the unsought finding. Serendipity: Origin, history, domains, traditions, appearances, patterns and programmability', The British Journal for the Philosophy of Science 45, 631-648. https://doi.org/10.1093/ bjps/45.2.631

Williamson, K., 1998, 'Discovered by chance: The role of incidental information acquisition in an ecological model of information use', Library \& Information Science Research 20(1), 23-40. https://doi.org/10.1016/S0740-8188(98)90004-4

Wilson, T.D., 1999, 'Models in information behaviour research', Journal of Documentation 55(3), 249-270. https://doi.org/10.1108/EUM0000000007145

Wilson, T.D., 2000, 'Human information behaviour', Special Issues on Information Science Research 3(2), 49-55.

Xuemei, G., 2010, 'Information-seeking behaviour in the digital age: A multidisciplinary study of academic researchers', College and Research Libraries 34(2), 435-452. https://doi.org/10.5860/crl-34r2 